\title{
TODOS LOS SANTOS. TRADICIÓN Y AYLLU ANDINO
}

\author{
TODOS LOS SANTOS. ANDEAN AYLLU AND TRADITION
}

\author{
Óscar Muñoz Morán ${ }^{1}$
}

\begin{abstract}
Los rituales dedicados a la muerte han ocupado siempre un lugar privilegiado dentro de la etnografía andina. Habitualmente analizados desde la funcionalidad o semiótica de los mismos, no ha sido habitual, como sí ha sucedido con otras prácticas regionales, encuadrarlas dentro de estructuras mayores. En este artículo me propongo analizar el momento actual de un ayllu quechua de Potosí, Bolivia, desde la lectura etnográfica (presente y pasada) de la fiesta de Todos los Santos. Esta festividad se presenta como el fiel reflejo del proceso de transformación intensa que está viviendo una estructura tan compleja como es el ayllu.
\end{abstract}

Palabras claves: Bolivia, Andes, ayllu, Todos los Santos.

The rituals dedicated to death have always occupied a privileged place within Andean ethnography. Usually analyzed from the point of view of their functionality or semiotics, they are not usually fit into larger structures, as has been the case with other regional practices. In this article, I propose to analyze the current situation of a Quechua ayllu in Potosí, Bolivia, from a (present and past) ethnographic reading of the festivity of Todos los Santos. This festivity is presented as a true reflection of the intense transformation such a complex structure as the ayllu is undergoing.

Key words: Bolivia, Andes, ayllu, Todos los Santos.

Por su carácter masivo y a la vez familiar, por los preparativos que supone y por su riqueza ritual esta fiesta es, en el campo, un momento culminante del ciclo ceremonial anual (...). Es un tiempo sagrado en que se celebra la llegada anual de las almas, es decir, los difuntos, que siguen viviendo pero de otra forma. Su ubicación a principios de noviembre, cuando concluye la estación seca y de mayor hambre, de agosto a octubre, y empieza la época de lluvias, no es casual (...). Marca el principio de la época de restauración, equilibrio y armonía con la naturaleza, y la época de siembras, que inician la estación productiva. La muerte personal y su descenso al seno de la Madre Tierra es la semilla de la nueva vida cósmica. Los muertos 'crían la vida' (Albó 2007:143).

Es común que durante el trabajo de campo los informantes se esfuercen por hacernos entender que aquello que nosotros estamos etnografiando con tanto entusiasmo, en realidad es una deriva moderna y poco romántica de un pasado mucho más interesante, más tradicional e indígena que ya desapareció o está en vías de ello. Hablar de una estructura familiar, de un sistema de cargos o de una fiesta con un amerindio es escuchar narraciones de cómo era en el pasado, más que una descripción sobre el presente.

Este texto presenta una comparación entre uno y otro momento en lo que se refiere a una de las fiestas más importantes del mundo andino: Todos los Santos. Describiremos la fiesta en una comunidad de Bolivia en la actualidad y la compararemos con lo que los locales narran que sucedía en el pasado. El objetivo no es mostrar los elementos que se han perdido o aquellos que se han visto transformados. $\mathrm{La}$ intención es usar esta comparación para reflexionar acerca de una cuestión de suma importancia para la comunidad y de actualidad hoy en Bolivia: la situación actual de los ayllus, su desestructuración y el intento de reconstitución de los mismos.

Desde hace unas décadas existe por parte de una cierta intelectualidad indígena boliviana, un intento por lo que se ha denominado "reconstitución del ayllu" (p.ej. Choque 2000; Choque y Mamani 2001). El ayllu es considerado como la esencia misma de la identidad prehispánica de la población boliviana,

1 Departamento de Historia de América II (Antropología de América), Universidad Complutense de Madrid, España. ommoran@ghis.ucm.es 
de tal forma que pervive hasta la actualidad aunque claramente pervertido por el elemento colonial. Se ha conservado, no obstante, su apuesta por los valores y las tradiciones, por lo propio, por la autogestión del territorio y el gobierno local. Actualmente "en el altiplano se vive el retorno al ayllu, que en términos propios es entendido como Pachakuti, que quiere decir el retorno de nuestra autoestima y la identidad (...)" (Choque Quispe 2000:15). Una estructura que ha sobrevivido a todos los intentos que ha habido a lo largo de la historia por destruirlo. Una estructura que representa el sentir de una subalternidad en la sociedad colonial boliviana y que debe ser piedra angular de la descolonización del país (Choque Quispe 2000:21).

Lo que interesa resaltar de esta postura es que estos autores reconocen que el ayllu se ha visto, pese a todo, claramente transformado. Que hoy se presenta, al igual que otras muchas estructuras prehispánicas, como un producto del colonialismo. Es cierto que el ayllu sigue siendo la unidad básica de organización social (cultural, podríamos decir) de gran parte de los Andes, pero también es verdad que, como intentaré mostrar en este texto, está viviendo unos momentos complicados en cuanto a su estructura interna ${ }^{1}$.

En las siguientes páginas, por tanto, vamos a presentar cómo los cambios en ciertas tradiciones son el fiel reflejo de un tiempo complicado para la idea tradicional de ayllu (al menos en los casos conocidos del Departamento de Potosí) presentada por la literatura andina que le ha concedido especial importancia al elemento diacrónico ${ }^{2}$. Como indicaba Isbell

Los datos históricos asumen que el ayllu andino no puede ser una institución sin cambios; una institución primordial que se ha resistido a las influencias externas durante siglos y quizás milenios (Isbell 1997:132).

Asumimos, entonces, que la discusión actual sobre los ayllus andinos nos debe llevar necesariamente a analizar sus cambios, ya que parecen ser más importantes y ocupar más espacio que sus permanencias. Aunque, eso sí, como precisa Sendón:

Aunque el ayllu en su versión temprana no tiene por qué coincidir con las versiones contemporáneas que se tiene acerca de él, ello no involucra que algunos aspectos identificados sobre la primera no puedan ser fuente de reflexión acerca de las segundas (Sendón 2009:109).

No es el objetivo de este texto, por tanto, intentar establecer una definición de ayllu, aunque, como mostraré en las conclusiones, se considera indispensable dar algunas nociones de lo que los propios comunarios dicen al respecto.

\section{Todos los Santos en el Coipasi Actual}

La fiesta de Todos los Santos en la comunidad de Coipasi ${ }^{3}$ ocupa los primeros cuatro días del mes de noviembre, siendo el día 1 y el 2 los más importantes, ya que en ellos es cuando se interactúa con las almas de los muertos. La festividad se caracteriza en la actualidad, en comparación a cómo la describen los comunarios de décadas pasadas y que veremos más adelante, por su sencillez, por su diversidad, por la incorporación e importancia de ritos alternativos, pero, y al mismo tiempo, por conservar parte de lo que se considera tradición. Espero que la descripción etnográfica que sigue pueda ayudar a entender estos calificativos.

El 1 de noviembre es el día elegido por los evangélicos para recordar a sus fallecidos. Los católicos están ya en plena festividad y preparando los siguientes días, pero son las casas y celebraciones evangélicas las que ocupan el protagonismo este día. En concreto, en el año 2011 pude asistir al que se realizaba en honor a la recientemente fallecida doña Angélica. Lo sorprendente de este acto y que habla bien a las claras de la buena convivencia entre católicos y protestantes en la comunidad, es que la fallecida era evangélica pero su marido, don Vicente, no (hecho que no suele ser habitual, aunque tampoco único) ${ }^{4}$. No obstante este, y respetando los deseos de su mujer, le preparó una celebración al modo protestante. Estos, al igual que los católicos aunque sea menos habitual escucharlo, llaman a la mesa ritual preparada para la celebración "tumba" y se encuentra situada en el interior de una pequeña estancia de la casa del viudo. La habitación, de unos seis metros de largo por cinco de ancho, con una puerta y una única ventana de reducido tamaño, está oscura, únicamente iluminada por las luces de las velas y las que entran por los huecos de la estancia. La "tumba" se encuentra enfrente de la 
puerta y consiste en una sencilla mesa cubierta por un paño negro sobre el que se sitúan tres pirámides de panes. Entre dos de ellas había un plato con comida. Todo el paño está cubierto de "flores de la ilusión" (Gypsophila) a modo de alfombra y en encima un bastón de mando. Sobre la mesa se apoyaba otra más pequeña, centrada y donde estaba depositado un retrato de la difunta acompañado también de tres pirámides de panes y flores.

En la distribución de la sala tienen especial protagonismo, además de la familia nuclear de la difunta, los denominados "ministros" evangélicos (Figura 1) ${ }^{5}$. Esta primera parte de la jornada, que duraría como unas 3 horas, se caracteriza por su solemnidad y recogimiento, consistiendo principalmente en la entonación continua de himnos, tanto en quechua como en castellano. Todos los participantes fungen, en realidad, como "rezadores", una figura tradicionalmente descrita en la etnografía andina.

La mayoría de los cantos se realizan a petición del ministro principal de la iglesia evangélica de Coipasi, don Guillermo (que ese año además era el kuraka de la comunidad ${ }^{6}$ ), de un joven ministro que llegó de fuera de la comunidad y de alguna mujer. Además, don Guillermo leyó el que sin duda es su pasaje favorito de la Biblia, Lázaro y el hombre rico ${ }^{7}$, durante unos 45 minutos. Tras dos oraciones más ejecutadas por los otros dos principales ministros, se dio por finalizada la ceremonia.

Entonces comenzó el acto más lúdico de la jornada, que se trata de una comida informal y de tono alegre que se celebra en el patio de la casa.
Con una duración aproximada de dos horas es una actividad relajada, donde, por supuesto, no circula el alcohol. El producto principal de la comida era un chancho que la familia de la difunta se había encargado de matar y preparar los días anteriores. $\mathrm{Al}$ acto acude toda la comunidad evangélica (unas 20 personas), los familiares de la difunta y algún vecino más del pueblo, aunque no muchos. Durante ese tiempo, anexo al patio hay una pequeña habitación donde el encargado principal de prestar servicio (el $k^{\prime} u c h u$ ), distribuye los panes y las bebidas ${ }^{8}$. Tras la comida, en la tarde y hasta el atardecer, se continúa con la ceremonia religiosa en el interior de la estancia donde está "la tumba".

La tarde-noche del día 1 de noviembre se reserva para los actos (tanto católicos como protestantes) en el cementerio. En algunos casos se vela a las almas de los muertos tres noches seguidas, pero lo común es que las familias concentren la velación para la noche del 1 al 2 de noviembre. Eso me dijeron, pero en realidad la asistencia al cementerio se limita de las 18 a las 21 horas del día 1, quedando el panteón desierto en la noche.

El cementerio de Coipasi es de tamaño reducido y como la mayor parte de los de la región, no está cuidado, aunque sí cercado y el resto del año cerrado. Las tumbas se encuentran, por lo general, en estado de ruina y los matorrales y hierbas crecen en cada rincón. Además, suelen hallarse restos de la celebración del año anterior, así como, en algunos casos, de tierra y piedras de tumbas removidas (Figura 2). Es decir, a diferencia de los descritos en otros lugares de los Andes (Rojas 1995:228-229),

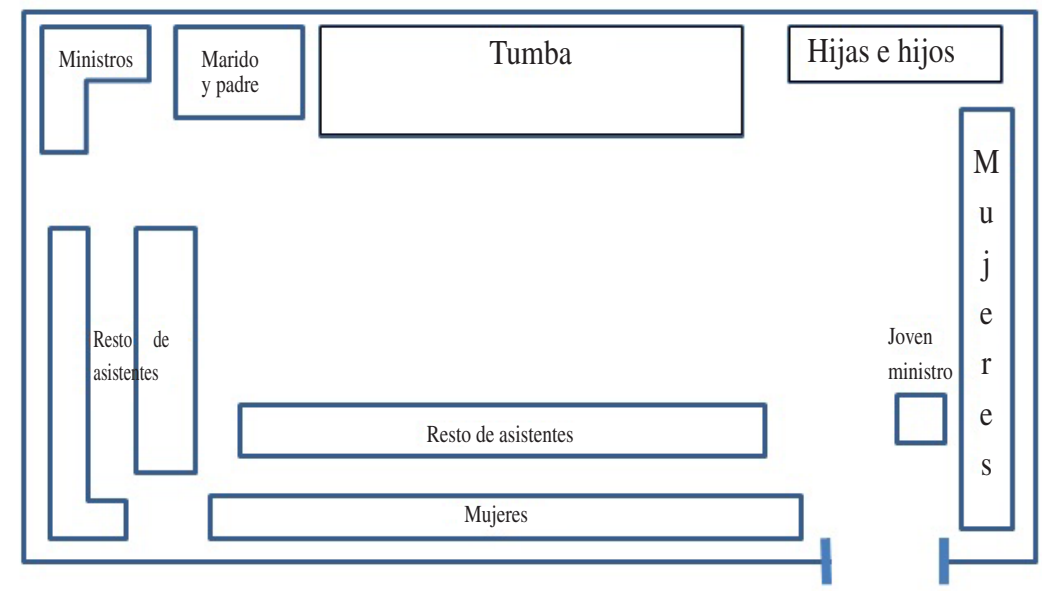

Figura 1. Distribución y ubicación de los asistentes al evento protestante. Distribution and location of the attendees at the Protestant event. 
el cementerio no se limpia y arregla antes de la fecha, más allá de las tumbas que van a ser objeto de devoción.

En el año 2011 no eran más de 10 las familias que estaban velando el alma de sus difuntos, principalmente aquellas que han fallecido en los últimos años. Las tumbas son adornadas modestamente: algunas pequeñas velas y flores y ofrendas a modo de botellas de alcohol principalmente (Figura 3). No obstante, como también se ha registrado para otros lugares de Bolivia (Rosing 1988) hay claras diferencias entre las tumbas de los comunarios acomodados y aquellas de familias de una modesta posición. Durante el acto del cementerio, la mayor parte de los presentes que no sean niños, se encuentran ya en estado de embriaguez por el consumo de alcohol. No obstante, se podían escuchar rezos y cánticos en algunas de ellas.

El día 2 de noviembre es el día reservado para el culto católico. Es decir, el día en que los católicos que han fallecido en el último año son velados en sus domicilios. En concreto, en el año 2011 únicamente se celebró en casa de don Pedro Cayampi, cuya esposa había fallecido muy joven hacía unos meses. La celebración, multitudinaria, se concentra en el patio de la casa, alrededor del altar ("tumba") realizado para la ocasión. Cuando yo llegué a dicho patio, tuve una sensación muy parecida a la descrita por Harris 30 años antes en el cementerio de los laymi:

después de algunas horas las emociones llegan a un crescendo. Cuando me tocó presenciar esta fiesta en el Altiplano, unas pocas semanas después de mi llegada, el caos era indescriptible (...) Por todas partes la gente estaba borracha, llorando y recitando oraciones (...); abrazábanse unos con otros y apelaban a sus muertos (Harris 1983:142).

El caos que me encontré al llegar a la casa de don Pedro, justo después del almuerzo, resultaba

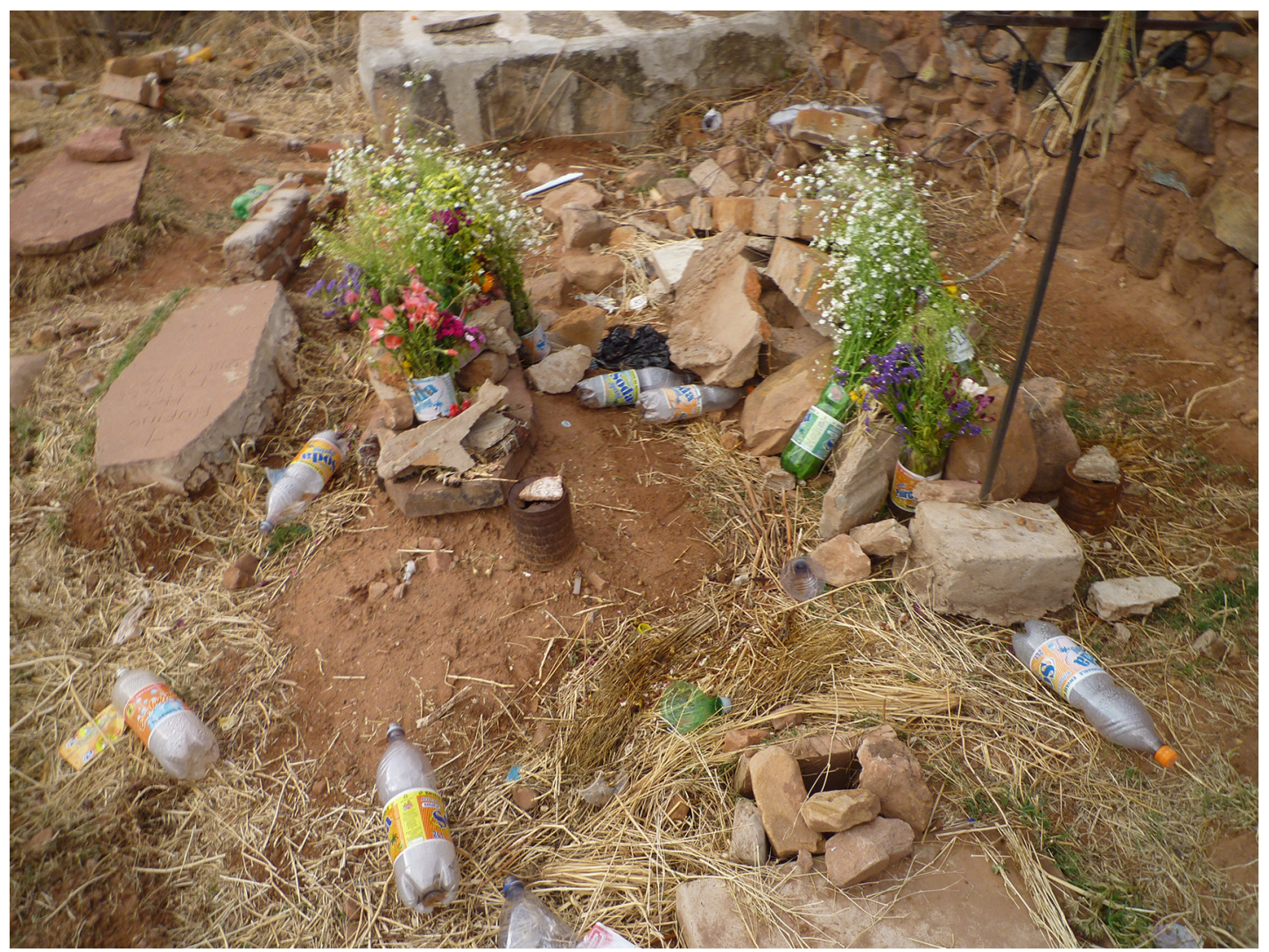

Figura 2. Tumbas con restos de celebraciones de varios años.

Tombs with remains of celebrations of several years. 


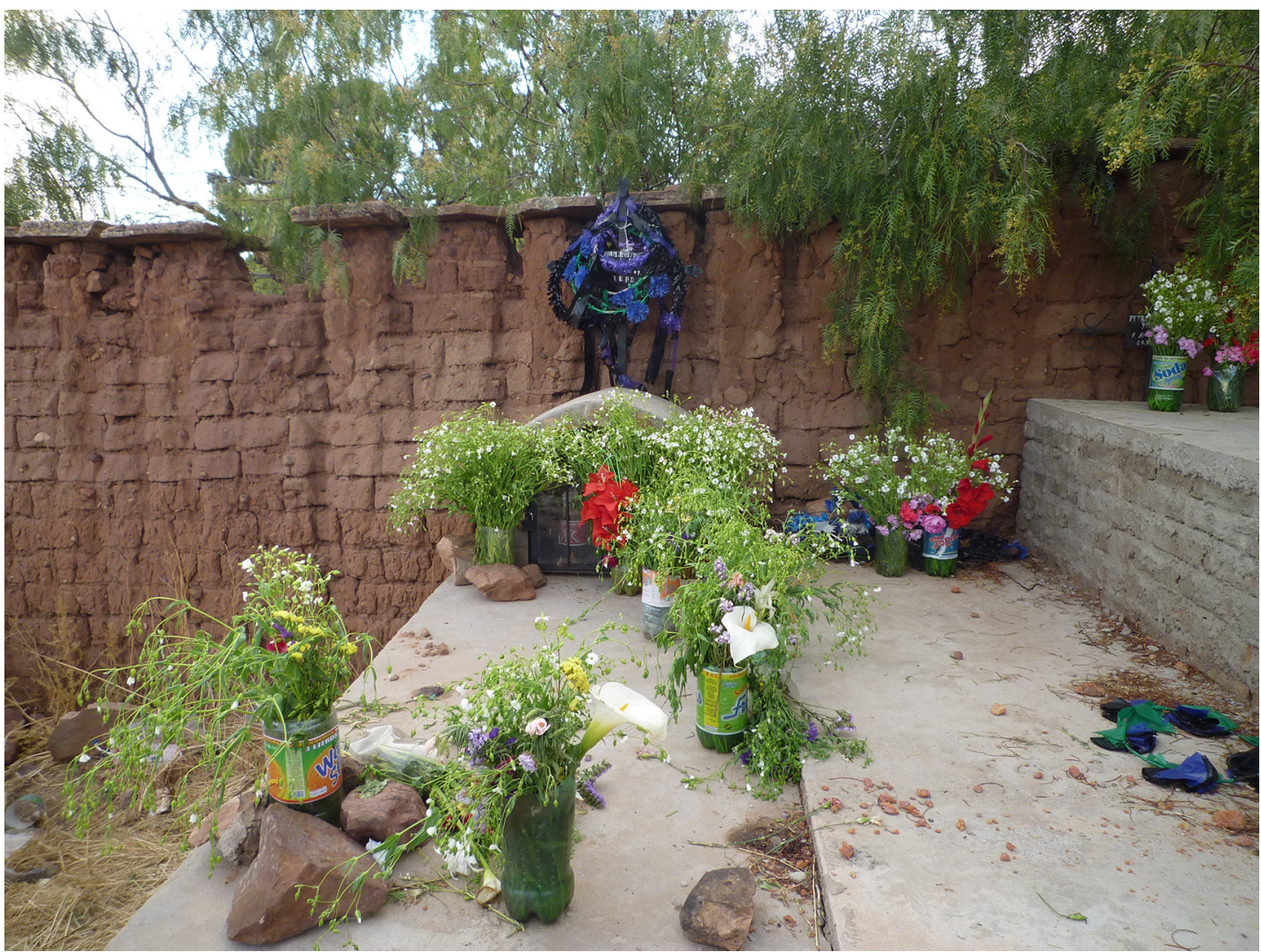

Figura 3. Una tumba decorada con flores modestas.

A tomb decorated with modest flowers.

realmente complicado de gestionar y el ambiente era diametralmente opuesto al del día anterior en la celebración evangélica. Excepto las mujeres jóvenes y los niños, el resto se encontraba en estado de gran embriaguez. Había discusiones y conatos de pelea. Las mujeres mayores, ebrias, se abalanzaron sobre mí con la intención de que bebiera de las muchas botellas con alcohol que circulaban. Los pocos hombres que se encontraban más o menos sobrios me invitaron a sentarme junto al viudo y el padre de la difunta, a un costado del altar. Este ocupaba el lugar central del patio y aunque resulta complicado pensar que allí existiera un cierto orden, sí es cierto que a un costado del altar se encontraban los familiares directos de la difunta, al otro los hombres adultos; y en cierta forma, retiradas y cercanas a la puerta de salida, las mujeres jóvenes y los niños.

Más allá de las impresiones de los antropólogos, es importante recordar, como ya han hecho otros autores, la importancia de la embriaguez para el duelo andino. El alcohol permite no solo ahogar las penas, también facilita la alteración de conciencia que le permite al familiar acercarse al mundo de los muertos y, por tanto, del alma del recientemente fallecido (Molinié 2015).

Tomar indica un aumento de fuerzas. Como excitante, el alcohol contribuye a unir a los hombres entre sí y con los espíritus, dioses o muertos (su uso anula la división entre esferas profanas, sagradas) (Saignes 1993:44).

Durante horas, las conversaciones a voces fluían de un grupo a otro. En las de los familiares directos era común mencionar a la difunta y las mujeres acababan llorando y lamentando su muerte. Tanto el marido como el padre intentaban atender a todos los presentes, obsequiándoles con alcohol, coca o panes. Aunque su estado de embriaguez fue en aumento y cada vez le fue más imposible realizar esta tarea. Cuando esto ocurrió, sus hijos 
adolescentes, que estuvieron siempre presentes, se hicieron cargo de las obligaciones. También les ayudaba, como hizo durante toda la jornada, el k'uchu, don Ángel Rodríguez, que al igual que en la celebración evangélica del día anterior, tenía una pequeña habitación anexa al patio habilitada para la preparación de bebida y la distribución de panes.

En cuanto al altar se refiere, hay que resaltar su presencia y belleza, haciendo sin duda honor a lo que los coipaseños cuentan de la celebración del ayllu en el cementerio en tiempos pasados y que veremos posteriormente. Se trata de un altar escalonado en siete pisos, con una altura aproximada de cuatro metros. Cada uno de los pisos es responsabilidad de un familiar, normalmente hijos o ahijados. Por tanto, el número de pisos depende de la cantidad de familiares que quieran asumir su formación.

La decoración es similar a la vista el día anterior en "la tumba" evangélica pero más profusa: un paño negro cubriendo cada una de las mesas y alfombrado con flores de la ilusión. Encima varias pirámides de panes de distintas clases (tauqa), colores y acompañados de otros objetos como botellas de alcohol, platos con comida, bastones de mando y un crucifijo coronando el último piso (Figura 4) ${ }^{9}$. Muchos de los panes presentan formas antropomorfas, como en otras regiones andinas donde se describen como las representaciones de las almas que se esperan:

\begin{abstract}
Representan a las almas de los difuntos que van a ser convidados. Se las llama t'ant'awawas, 'bebés de pan', si representan a niños, y t'ant'a achachis, 'abuelos de pan', si representan a adultos. Con frecuencia llevan caras pintadas y, a veces, también el nombre o los iniciales del difunto (Van den Berg 1989:160).
\end{abstract}

Sin duda alguna, la forma de la "tumba" nos lleva inmediatamente a pensar en un "lugar límite" de las almas (Fernández 2001) ${ }^{10}$, una especie de estructura (escalera o "gradas", como le dicen en

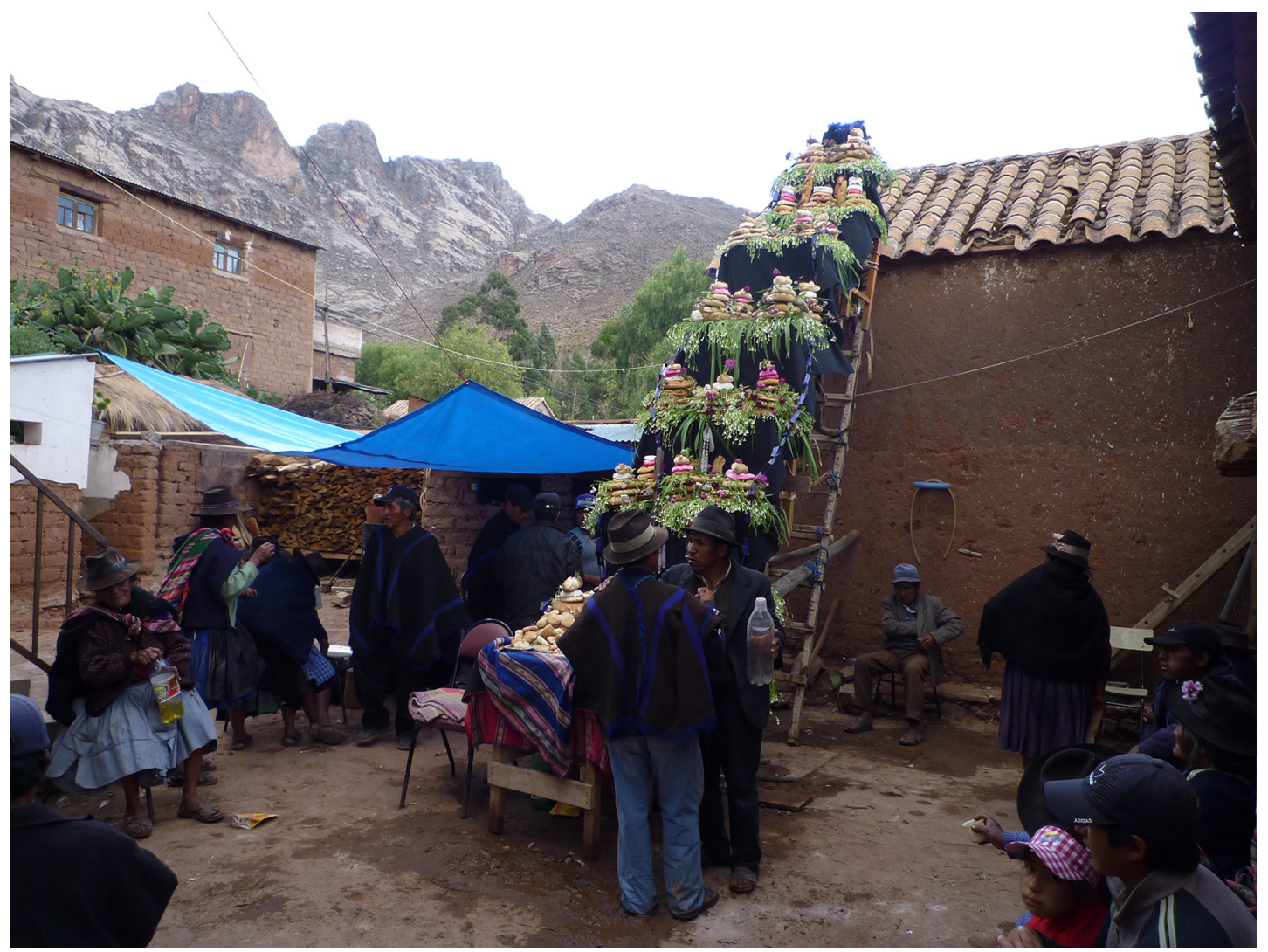

Figura 4. El altar o "tumba" en el patio de don Pedro Cayampi.

The altar or "tumba" in the courtyard of don Pedro Cayampi. 
la comunidad) destinada a que las almas asciendan al lugar que les corresponde, ya que cuando en Coipasi se pregunta a dónde van las almas de los muertos, se contesta que al cielo. No obstante, no encontré en ningún momento una explicación por el estilo a esta significación simbólica.

El desmontaje del altar, que comienza a las 17 horas, es uno de los puntos álgidos de la celebración. Los encargados de ello son los más jóvenes (dicen que por "livianos") y la primera tarea es repartir los panes entre los presentes. Se realiza con todos excepto los de las dos primeras mesas (aquellas que pertenecen al viudo) que se reservan para elaborar el altar más pequeño que quedará para la tardenoche. El resto de panes pueden ser recogidos por las "mamas" pero solo aquellas que pertenecen al grupo familiar de la difunta. El desmontaje de la estructura es un acontecimiento del que están pendientes todos los presentes. Entre otras cosas por la peligrosidad, pues es precisamente por las caídas en este momento por lo que muchos coipaseños afirman que se dejaron de elaborar para la celebración en el cementerio. Muchos de los que subieron estaban en estado de embriaguez, aunque fueron inmediatamente retirados, sobre todo por el k'uchu, don Ángel, que se encargó de la mayor parte del desmontaje aunque con ayuda (Figura 5).

El altar resultante es mucho más pequeño y formado de una única altura. Allí se concentran los panes de las dos primeras alturas anteriores, así como algunos objetos $y$, principalmente, cuatro botellas ceremoniales con chicha, y cuyo cuello llevaba atado un pequeño paño. Estas botellas, una vez finalizado el desmontaje, fueron ofrecidas a los jóvenes encargados del mismo y uno de ellos se dedicó a repartir la chicha entre los presentes.

Los invitados acuden siempre a la casa de la celebración con una o varias bolsas de plástico donde poder guardar los muchos panes con los que son obsequiados ese día ${ }^{11}$. En concreto hay dos tipos de panes que los asistentes nos llevamos

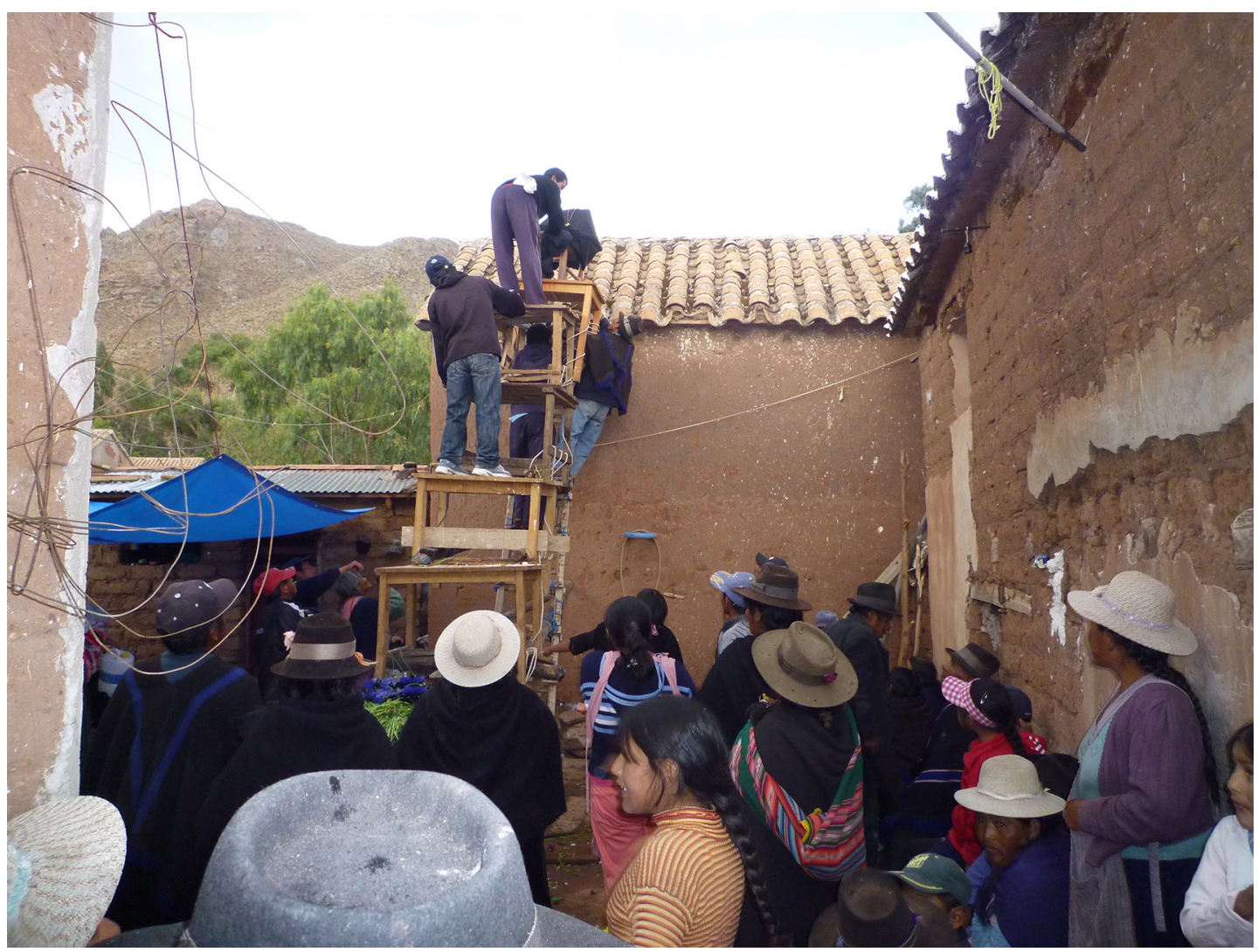

Figura 5. Desmontando la "tumba".

Taking apart "la tumba". 
para nuestras casas: los que estaban en el altar de mayor tamaño, aunque estos más limitados y reservados en gran medida para los familiares directos, son más difíciles de conseguir; y unos panes en miniatura que se encuentran dentro de la casa y que sacan exclusivamente para repartir, es decir, no son expuestos. Entre estos pequeños panes abundan los que tienen forma de animales ${ }^{12}$.

Llegados a esa altura de la jornada, es extraño el adulto (principalmente los hombres de todas las edades y las mujeres mayores) que no está ebrio. Incluso ese año en concreto, fue muy comentado en días posteriores la borrachera del corregidor y su mamathalla. Ya al final, fueron invitados a marcharse porque estaban especialmente contenciosos. La particularidad de esta situación no venía por esta actitud o su cargo, sino porque son evangélicos. Fueron expulsados las semanas posteriores de la Iglesia evangélica por ello, aunque hoy en día han regresado de nuevo "al templo".

La fiesta continúa durante la tarde y parte de la noche y los dos días siguientes. El día 3 principalmente se dedica a jugar a palama o palamar como se suele nombrar en la comunidad, en la cancha de al lado de la casa ${ }^{13}$. Allí los hombres adultos, también bajo el efecto del alcohol, deben dejar la piedra que lanzan lo más cercana posible de un punto fijado. El juego se ha descrito a partir de que ese punto es representado por un hueso dentro de un pequeño hoyo hecho en la tierra (Van den Berg 1989:163). Aunque en Coipasi en ocasiones me lo refirieron así (por ejemplo, el que practican los niños), al menos el que yo presencié en esa ocasión el punto solo estaba marcado con una pequeña piedra de color blanco. El día 4 la fiesta continúa en la casa, donde se invita a chicha y a cordero aunque en un ambiente más relajado y con el altar resultante presidiendo.

\section{Una Mirada al Pasado. La Fiesta de Todos los Santos Narrada}

En realidad la forma de proceder descrita en esta etnografía es relativamente reciente. Los coipaseños, cuando se les pregunta por la fiesta de Todos los Santos fuera de las fechas indicadas, te narran siempre lo que ellos consideran las formas tradicionales de hacerla. Pero incluso te remiten constantemente a un tiempo más lejano, aunque todavía vivido por los más ancianos, donde ni siquiera tenían cementerio.
Cuentan cómo en las primeras décadas del siglo XX tenían que ir a enterrar a sus muertos al cementerio municipal de Chaquí.

Aquí yo me he casado. Aquellos tiempos, te estoy diciendo, yo tenía 34 y esto sería en el 25 , en el año de 1925, 24, por ese año, esa temporada ${ }^{14}$. El costumbre era de aquí. Ahora... no solamente eso. Aquí no había panteón, cementerio, no había. Y llevaban hasta allá. ¿Cuántos kilómetros será ese? No sé, ¿cuántos kilómetros serán de aquí a Chaquí?, no sé. Lejos. ¿Conoces Chaquí? Bueno hasta allí, por el camino por acá directo (Anastasio Huaranca).

Pero, sin duda alguna, lo que más se recuerda y narra de esa situación, es cómo se producía el transporte de los difuntos:

Y por eso a los finalitos [finaditos], llevaban hasta allá. ¿Sabes en qué llevaban? Dos palos puestos aquí, dos palos. Entonces abajo de los dos palos, abajo, para el peso del finalito... tendrían [que] ser palos, palitos. Sobresito, al hombro... al hombro (Anastasio Huaranca) ${ }^{15}$.

Por tanto, teniendo en cuenta que el cementerio de Coipasi parece ser relativamente reciente (las tumbas más antiguas son de la década de 1940 del siglo pasado), la festividad de Todos los Santos relacionada con el ayllu y comunidades vecinas apenas tuvo presencia durante unas décadas. Aun con todo es constantemente narrada como la forma "tradicional", como "el costumbre".

Según los coipaseños, la celebración entonces de los días 1 y 2 de noviembre era completamente diferente. En líneas generales no difería mucho de lo que han descrito otros autores para la región. Como señaló Harris para los laymi,

La organización espacial del cementerio reafirma la diferenciación dentro de la etnia; las tumbas están situadas de acuerdo a la división en mitad y también a las subdivisiones dentro de cada mitad. Cada parte del cementerio pertenece a una sección local de estos subgrupos. La división no es solamente espacial; a nivel de las mitades encuentra expresión en las peleas rituales 
(tinku) que se organizan para Todos los

Santos (...) (Harris 1983:142).

En efecto, todos los habitantes de Coipasi pueden recordar perfectamente cómo los miembros de todas las comunidades vecinas (no exclusivamente las del ayllu) venían a la fiesta de Todos los Santos, pues era costumbre que enterraran a sus muertos en el cementerio de esta comunidad ${ }^{16}$. Es muy complicado determinar qué comunidades enterraban a sus muertos en el cementerio de Coipasi pues prácticamente me fueron nombradas todas las que se encuentran cercanas (más de una veintena), lo cual me parece improbable teniendo en cuenta el tamaño del panteón. Fueran las que fueran, cada comunidad tenía su espacio reservado, hoy en día ya ocupado por completo por las del ayllu Coipasi. Además, como en todos los cementerios andinos, se reservaba una parte muy importante, la parte posterior del cementerio visto desde la puerta de entrada (el sureste), para los "angelitos" o "chicos", es decir, para aquellos bebés muertos antes de ser bautizados o incluso, los menores de cinco años ${ }^{17}$.

La fiesta de Todos los Santos era el momento donde más gente se reunía en la comunidad. El día de San Pedro, patrón del ayllu, congregaba a los miembros del mismo, pero como hemos visto, para Todos los Santos además de estas comunidades, venían otras vecinas a festejar a sus muertos. Por tanto, el recuerdo de un cementerio y de la pampa anexa repletos de personas, es una constante en las conversiones coipaseñas.

En el cementerio, además, todos aquellos que habían tenido un fallecido a lo largo del último año, hacían un altar (denominado "tumba", como ya hemos visto) al modo visto para el presente en casa de don Pedro, que ponían junto a las sepulturas. Así, el cementerio se convertía en un espectáculo de altares que competían entre sí por ser los más altos y mejor dotados del lugar, así como un verdadero hervidero de actividad ${ }^{18}$.

De aquí alrededor. No había cementerio, ni Kona Phaya, ni en ... aquí ... puuuuucha, pa' todas las gentes, lleeeeeenito este cementerio. Asito la gente. Como si en tumba así plantaran palo y armaban así con mesas. Así más o menos, cinco, seis mesas así de alto. Y ahí cada mesa le ponían tortas y al ladito estaba una silla (...)
Así como en forma gradas sería, así. En forma gradas, así, se ponían las mesas. Y ahí en cada mesa sabían, ponían tortas, bien floreado. Así más antes sabían hacer en Todos los Santos (Valeriano Huaranca).

El cementerio, que se convertía así en el símbolo de la comunalidad (Bastien 1996:218), era el lugar también donde se realizaba otro de los rituales más importantes: el tinku, algo común en esta región como han mostrado otros autores (Harris 1983; Van den Berg 1989) ${ }^{19}$. El tinku se ha descrito habitualmente como una de las ceremonias por medio de las cuales se miden las fuerzas dentro del ayllu, al mismo tiempo que sirve para reafirmar alianzas. Es decir, un medio usado por las comunidades dentro del ayllu para afianzar el mismo y las posiciones de cada una de ellas.

$\mathrm{Al}$ menos en el caso del ayllu Coipasi, el que durante Todos los Santos se celebrara el tinku tenía precisamente esto como objetivo. Además de, como he escrito en otro lugar (Muñoz 2016), tal vez el tinku funcione como una especie de chaupi o encuentro entre fuerzas diferentes. En este caso, el mundo de los vivos y el mundo de los muertos ${ }^{20}$.

\section{Desestructuración del Ayllu}

Todos los coipaseños son conscientes de que la celebración conjunta se ha perdido y ahora ha cambiado de forma radical como nos resume don Anastasio Huaranca:

Claro, mucho tiempo ha durado eso. Ahora esto se ha perdido totalmente. Ya no se hace. El costumbre está borrado totalmente. Ahora cuando uno viene para Todos los Santos, en su casa nomás ya, una mesa, pone dos velecitas y listo. Ya en el cementerio, pueden poner velitas ya nomás. Entonces ya, a la altura como cinco, seis metros de alto. Mesas, escalitas, así. Yo también, de joven, todavía estaba... chupando el trago y todo y una vez me caí...

Cuando se pregunta por las causas por las que el resto de comunidades dejó de venir a celebrar al cementerio de Coipasi lo común es que se haga alusión a la peligrosidad de esa celebración. Tanto a la más que obvia de los tinkus o peleas rituales, como a las muchas caídas sufridas montando, pero 
sobre todo desmontando los altares rituales como le sucedió al mismo don Anastasio. Todas ellas, por supuesto, agravadas por el consumo de alcohol.

Pero en realidad hay razones estructurales que poco tienen que ver con las posibles caídas desde lo alto del altar pues, como hemos visto, estos se siguen construyendo.

Las razones del abandono y transformación de la fiesta regional de Todos los Santos en Coipasi son principalmente tres que voy a pasar a describir y que por otra parte, podemos prácticamente usar de igual forma para explicar todas las transformaciones a nivel ayllu que se han producido en el lugar.

Por un lado la despoblación de las comunidades debido a la emigración masiva de los jóvenes tanto a las ciudades del país como, y principalmente, a Argentina. La falta de población joven está planteando verdaderos problemas a estas comunidades tanto en la continuidad de tradiciones (por ejemplo, la elección y renovación de las autoridades originarias) como de la actividad económica tradicional (abandono del cultivo de tierras y escasez de productos que cada vez hace más necesario adquirir en el mercado regional de Betanzos. Pero también la profesionalización de los jóvenes, especialmente en el sector educativo o sanitario).

Por otra parte la creciente presencia de los evangélicos en la comunidad ha provocado que el seguimiento de determinadas festividades no sea igual que hace unas décadas. La actitud habitual de los evangélicos es la de criticar abiertamente todo lo que tenga que ver con la tradición local, pero más allá del discurso existe un intento consciente de no abandonar del todo esta tradición (Muñoz 2014). Para ello, como hemos visto en el caso del día de Todos los Santos, se crean nuevas prácticas que funcionan como transición entre lo propio y lo nuevo, entre el conocimiento local y los preceptos bíblicos. No obstante, no se puede negar la incidencia de estos cambios en la estructura general comunaria: la intimidad del acto ya que este se realiza en las casas (incluso en el interior de las mismas y no el patio como es el caso de los católicos) y se renuncia a la celebración pública en el panteón; la desaparición en las fiestas del alcohol, de los bailes, de los trajes tradicionales o cualquier elemento lúdico que sirve comúnmente para hacer grupo.

En último lugar, y en lo que se refiere a la desestructuración del ayllu, en Coipasi hay un hecho causal que actuó como condicionante de que el resto de comunidades acudieran cada vez con menor frecuencia a las fiestas de la cabecera, Coipasi. En el año 1994 tras un descuido de una autoridad local, se quemó la figura de San Pedro unos días antes a su fiesta. Esta misma autoridad decidió hacer dos figuras nuevas, lo cual fue el principio del fin de la fiesta local. Esto se debe a que hasta entonces, el ayllu debía de ir a buscar la figura a la iglesia de la capital municipal, Chaquí. El recorrido ritual que hacía la imagen desde esta localidad hasta la iglesia parroquial de Coipasi obligaba a pasar por todas y cada una de las comunidades del ayllu, visitar las casas de las autoridades locales e invitar a todos sus habitantes a la fiesta mayor en el pueblo de Coipasi. Tras la quema de la figura, la autoridad local decidió hacer dos nuevas figuras: una para depositarla en la iglesia de Chaquí y otra en la de Coipasi. Por tanto, desde ese momento el resto del ayllu dejó de sentirse parte de la fiesta patronal al eliminarse el recorrido ritual que acompañaba al traslado del santo. Los informantes aseguran que más o menos desde entonces también comenzó a dejarse de celebrar de forma conjunta Todos los Santos.

La problemática de la pérdida de importancia del sistema de autoridades no viene solo determinada por este hecho. No podemos dejar de mencionar los muchos conflictos al interior del ayllu que hoy están surgiendo. En realidad existen tres kurakas en el mismo: uno para Ura Coipasi en la comunidad de Chaquí Baños y otro para Pata Coipasi en la comunidad de El Palomar. El kuraka principal o mallku, es el de la comunidad de Coipasi y los otros dos deberían de estar supeditados a él. Hoy tanto Chaquí Baños como El Palomar han potenciado sus autoridades, de tal forma que prácticamente ejercen de forma independiente las tres. Existen tres problemáticas que han dado lugar a esto: en lo que respecta a Chaquí Baños esta es una comunidad fuerte económicamente y de gran potencial turístico gracias a los famosos baños termales que tiene en sus terrenos. Esto le ha llevado a realizar peticiones y políticas de desarrollo al margen del resto del ayllu que han molestado en las otras comunidades (además de que Coipasi reclama que uno de los ojos de agua de los baños termales está en las tierras de un coipaseño y deberían de ser ellos quienes lo gestionaran); en lo que se refiere a El Palomar, esta 
comunidad ha sido siempre ciertamente ignorada por sus compañeras al ser exhacienda y, por tanto, no originaria y no considerada indígena; $y$, por último, como los mismos coipaseños reconocen, ellos han provocado el enojo de otras comunidades pues el kuraka principal, el mallku, debería de turnarse anualmente entre el resto de localidades, y actualmente apenas hay recuerdo de cuándo sucedió eso por última vez.

\section{Conclusiones}

En un reciente trabajo, De la Cadena ha introducido una noción tal vez novedosa sobre lo que el ayllu significa para los andinos. Para ella, el ayllu no se refiere a una institución, sino a una posición en el mundo, una posición ontológica. Ser ayllu es interrelacionarse con los humanos y con los otros seres que pueblan el paisaje andino. Es vivir y experimentar un paisaje y unos lugares comunes (De la Cadena 2015). Creo que su concepto está relacionado con la idea de acumulación de experiencias entre humanos y otros seres o espíritus que ya propuso Lienhardt (2003) para los dinka de Sudán.

Pero sin duda, está estrechamente vinculado, como ella misma cita, con el propuesto por Allen en Sonqo y su idea de common focus, es decir, an ancestor, a Sacred Placed claiming their common allegiance, an individual claiming them as kinsmen, a common specialization, ore ven a shared task (Allen 2002:87).

Interesa especialmente resaltar de estas propuestas tres ideas fundamentales y claramente relacionadas entre sí: espacio-territorio, vínculo común y experiencias. Estos tres elementos nos pueden ayudar a entender mejor la imprecisión y en algunos casos contradicción, con las que los comunarios nos definen ayllu durante el trabajo de campo.

En Coipasi se recurre constantemente al ayllu para explicar las relaciones de parentesco, la posesión de las tierras, el sistema de autoridades o cargos, las festividades o la economía. Cuando se hace la pregunta, tal vez improcedente, de qué es un ayllu, la respuesta siempre se resume en una palabra: familia. Porque las relaciones dentro del ayllu son las relaciones con la familia extensa que se distribuye por el mismo. Pero estas relaciones se traducen en reciprocidades, intercambios y visitas mutuas en los días festivos.

Como he mencionado, los coipaseños afirman haber abandonado progresivamente estas relaciones pues ya no visitan a sus familiares o han dejado de trabajar las tierras que poseen en otras partes del ayllu. El ayllu es en la actualidad una unidad espacial, claramente determinada por las comunidades que lo configuran y por los mojones que cada cuatro o cinco años se debe de encargar de recomponer la autoridad principal.

Por otra parte, la emigración ha provocado que muchos familiares ya no estén ni para visitar ni para ser visitados. Pero también que debido a esta ausencia no se pueda mantener un sistema de cooperación en el mantenimiento de las chacras que era fundamental. Es decir, una misma persona lograba tener tierras cultivadas en varias comunidades y/o pisos ecológicos gracias a la ayuda de los familiares que allí vivían. La ausencia de estos familiares ha provocado el abandono de las tierras y con ello de una parte importante de la economía local. Los jóvenes ya no quieren dedicarse al campo y cada vez son más los que emigran o se hacen profesionales. Los evangélicos, cada vez más presentes, no participan de las fiestas ni de los intercambios, lo cual provoca que la presencia en estas sea muy reducida. Por tanto, la estructura que mantiene en pie el complejo mecanismo del ayllu se tambalea.

La descripción etnográfica aquí presentada sobre la fiesta de Todos los Santos en un pequeño ayllu de Potosí tenía como objetivo mostrar la situación actual en la que este se encuentra y convertirse en un campo de reflexión sobre la realidad del mundo andino. 


\section{Referencias Citadas}

Albó, X. 2007. Muerte andina, la otra vertiente de la vida. En Etnografías de la Muerte y las Culturas en América Latina, coordinado por J.A. Flores Martos y L. Abad González, pp. 137-154. Universidad de Castilla-La Mancha, Cuenca.

Allen, C.J. 2002. The Hold Life Has. Coca and Cultural Indentity in an Andean Community. Smithsonian Books, Washington, DC.

Bastien, J.W. 1996. La Montaña del Cóndor. Metáfora y Ritual en un Ayllu Andino. Hisbol, La Paz.

Camino, L. y J.L. Yamunaqué 1987. La permanencia de formas andinas en las ceremonias de difuntos en el Bajo Pirua. Boletín de Lima 49:59-64.

Choque, M.E. 2000. La reconstitución del ayllu y los derechos de los pueblos indígenas. En Las Sociedades Interculturales: un Desafío para el Siglo XXI, coordinado por F. García, pp. 13-30. FLACSO-IBIS, Quito.

Choque, M.E. y C. Mamani 2001. Reconstitución del ayllu y derechos de los pueblos indígenas: el movimiento indio en los Andes de Bolivia. The Journal of Latin American and Caribbean Anthropology 6:202-224.

De la Cadena, M. 2015. Earth Beings. Ecologies of Practice across Andean Worlds. Duke University Press, Durham and London.

De Reina C. y C. De Valera 2005 [1909]. La Santa Biblia. Bibles.org.uk, London.

Fernández Juárez, G. 2001. Almas y difuntos: ritos mortuorios entre los aymara lacustres del Titicaca. Chungara Revista de Antropología Chilena 33:201-219.

Harris, O. 1983. Los muertos y los diablos entre los laymi de Bolivia. Chungara 11:135-152.

Isbell, W.H. 1997. Mummies and Mortuary Monuments: A Postprocessual Prehistory of Central Andean Social Organization. University of Texas Press, Austin.

Lienhardt, G. 2003. Divinity and Experience. The Religion of the Dinka. Oxford University Press, Oxford.
Lara, J. 2010. Diccionario. Queshwa-Castellano, CastellanoQheshwa. Librería Editorial G.U.M, La Paz.

Molinié, A. 2005. Introducción. En Etnografías del Cuzco, compilado por A. Molinié, pp. 7-17. Institut français d'études andines, Centro de Estudios Regionales Andinos Bartolomé de Las Casas, Lima.

Muñoz Morán, Ó. 2014. El tiempo del diluvio. Interpretaciones evangélicas sobre el tiempo antiguo en el ayllu Coipasi, Bolivia. Revista Española de Antropología Americana 44:235-253.

Muñoz Morán, Ó. 2016. ¿Se puede hacer etnografía de los muertos? Reflexiones desde los Andes. Anales del Museo Nacional de Antropología XVIII. En prensa.

Nicolás, V. 2015. Los Ayllus de Tinguipaya. Ensayos de Historia a Varias Voces. Plural Editores, La Paz.

Platt, T. 2016 [1982]. Estado Boliviano y Ayllu Andino. Tierra y Tributo en el Norte de Potosí. Vicepresidencia del Estado, La Paz.

Rosing, I. 1988. La fiesta de Todos los Santos en una región andina. El caso de los 'médicos callawayas'. Allpanchis 32:43-71.

Saignes, T. 1993. Borracheras andinas. ¿Por qué los indios ebrios hablan español? En Borrachera y Memoria. La Experiencia de lo Sagrado en los Andes, dirigido por T. Saignes, pp. 43-71. Institut français d'études andines-HISBOL, Lima.

Sendón, P. 2009. Los ayllus de la porción oriental del departamento del Cusco. Aproximación comparativa desde el Collasuyu. Bulletin de l'Institut Français d'Études Andines 38:107-130.

Sendón, P. 2013. Un altar para los muertos. En Al pie de los Andes. Estudios de Etnología, Arqueología e Historia, editado por P. Sendón y D. Villar, pp. 33-45. Itinerarios - ILAMIS (Scripta Autochtona 11), Cochabamba.

Rojas Zolezzi, M. 1995. Segundas exequias en el mundo andino y la noción de alma. Anthropologica 13(13):221-235.

Van den Berg, H. 1989. La celebración de los difuntos entre los campesinos aymaras del Altiplano. Anthropos 84:155-175.

\section{Notas}

1 Cierto es que en cuanto a organización y presencia política se ha reforzado gracias al impulso del actual gobierno a los Consejos de Ayllus Originarios.

2 En lo que se refiere a Potosí, resaltar el reciente trabajo de Nicolás (2015) o el reeditado de Platt (2016).

3 Coipasi es la capital del ayllu y el cantón del mismo nombre situado en el municipio de Chaquí, Potosí, Bolivia, dividido en dos secciones: Ura Coipasi que comprende una pequeña parte de la comunidad de Chaquí Baños y algunas islas en Qollpa Pampa; Pata Coipasi, donde se ubica la misma Coipasi, Phalapaya, Villcamayu y El Palomar. La comunidad de Coipasi está situada en zona de valle con un clima benigno y un relativamente buen suministro de agua. Por tanto, sus habitantes son mayormente agricultores aunque, como en el resto de los Andes, el complemento de esta actividad con la cría de diferentes animales es fundamental. Los datos sobre el número de población son sumamente variables y poco fiables. Los últimos municipales de 2003 hablan de 1.627 habitantes en el conjunto del ayllu y 540 en la comunidad de Coipasi. No hay datos actualizados desde entonces, pero es evidente que las cifras, debido a la migración, se pueden haber reducido prácticamente a la mitad. De esa población, debemos indicar, por la importancia que tiene para este texto, que el porcentaje de protestantes está en torno al $20 \%$.

4 Por "buena convivencia" me refiero al hecho de que aunque existen mutuas críticas, el conflicto no se ha instalado en Coipasi y, de hecho, existen muchos más ámbitos de la vida cotidiana donde se colabora que donde se discrepa.

5 Los llamados "ministros" son los pastores de la iglesia evangélica local. En un número de tres personas, son los encargados de dirigir a todo el grupo así como los actos rituales. Ellos mismos se consideran los únicos capaces de poder leer, interpretar y manifestar correctamente la "palabra del Señor". 
6 El sistema de autoridades en Coipasi es relativamente sencillo en comparación con el descrito para otros lugares de la región. Hay tres autoridades principales con el siguiente orden según su importancia: el kuraka, el alcalde y el corregidor. Los dos primeros son considerados las "autoridades originarias". El kuraka es el mayor representante y se encarga de tomar las decisiones más importantes, convocar a la comunidad, presidir los actos y, lo que es más importante, tener la última palabra en la distribución de tierras (en caso de conflicto). El alcalde o justicia es, en palabras de los comunarios, "el segundo"o "hijo" del kuraka. El corregidor, por su parte, es un cargo poco querido, pues se considera claramente "político", ligado al partido en el poder. Además, el corregidor era la figura tradicional de mayor poder hasta hace un par de décadas, y sigue conservando gran parte de la responsabilidad en muchos casos no reconocida por la comunidad. Para poder ser elegido, cualquiera de ellos, debe de estar acompañado de su mamathalla, es decir, de su mujer o, en su defecto, de su mamá si se trata de una persona joven y soltera. Es decir, no puedes ser ch'ullu, solo, sin compañero.

7 Lucas 16: 19-31 (Reina Valera 2005 [1960]).

8 El encargado ese año, tanto para la fiesta evangélica como para la católica como veremos posteriormente, era don Ángel Rodríguez. Este me explicó que todos los años el "dueño de la tumba" elige a una serie de personas de su confianza para que le preste "servicio" (ayuda) durante toda la celebración. El que se encuentra al frente de este equipo de lo que él denominó "respenseros", es el k’uchu. Su labor era "repartir pan, trago nomás. Preparar también el trago" y recibir aquellos dones que los visitantes traen. El término k'uchu se debe al lugar que ocupa durante la celebración, es decir, una habitación, cuarto o rincón donde él se resguarda, se encuentran todos los bienes que se distribuyen (los adquiridos por los familiares y los llevados por los invitados) y donde se toman las decisiones sobre cómo realizar este reparto. Según el diccionario de Lara (2010:130) se refiere a "Rincón, esquina, ángulo".

9 Sendón ha registrado un altar de parecidas características aunque de menor tamaño en Marcapata, Cusco. En su caso pone el acento en el análisis simbólico de los productos del altar, los cuales "remiten a un fenómeno de -al menoscomunicación entre elementos provenientes de las 'tierras altas' y las 'tierras bajas' en este sector de los Andes surperuanos” (Sendón 2013:36). Algo parecido mostró Bastien años antes entre los kallawayas, donde "los tres niveles de la mesa simbolizaban la Montaña de Kaata, y sus patas el otro mundo" (Bastien 1996:215-216).

10 Este trabajo de Fernández Juárez (2001) se encuentra en un número dedicado a los ritos mortuorios andinos contemporáneos de Chungara Revista de Antropología Chilena.

11 La reciprocidad y la distribución de bienes (comida y bebida) es fundamental en toda fiesta amerindia, pero parece ser que se hace más evidente en las aquí descritas, es decir, en las destinadas a las almas. El alcohol que se consume durante todos los días de la festividad (excepto la chicha) es proporcionado por los invitados que acuden a las casas donde se velan los difuntos (siempre las botellas deben ser llevadas en número par). A cambio, los familiares de estos, se tienen que preocupar por tener suficiente comida (representada en los panes) para surtir a todos los presentes. Como dicen Camino y Yamunaqué (1987:63): "Las formas de culto a los muertos están íntimamente ligadas a los alimentos y bebidas".

12 Nos dice Van den Berg sobre estos panes: "Un segundo grupo de panes forman las figuras zoomorfas: llamas, ovejas, perros, aves, etc. Pueden representar el rebaño del difunto, pero también pueden servir, simbólicamente, como medio de transporte para el alma, en particular los auquénidos, el caballo o el águila" (Van den Berg 1989:160). La importancia de los panes en Todos los Santos ha sido ampliamente tratada en la literatura etnográfica, ver tan solo como ejemplo Fernández Juárez (2001).

13 Hay otros dos juegos para Todos los Santos: chunq'a que se refiere al desplazamiento de una piedra blanca grande cuyo objetivo es que se detenga parada; y tocola, una piedra dividida en dos partes con un cordón rojo. En la parte superior hay un agujero donde debe introducirse una moneda tirándola desde lejos.

14 Es evidente que aquí don Anastasio está ligeramente confundido respecto de las fechas. Él tiene ahora mismo 81 años de edad. Su confusión no se debe a una falta de conocimiento de la cronología occidental por los coipaseños, ya que esta está perfectamente integrada en la comunidad (las dataciones se registran en gran medida respecto de las siguientes fechas: matrimonio, primer año de migración a Argentina o autoridades tradiciones ocupadas).

15 Ir a Chaquí siempre ha sido para los coipaseños una tarea ardua. Para llegar caminando a la capital del municipio deben atravesar los cerros más importantes que circundan a la comunidad (por el llamado "Camino inca") durante unas cuatro horas o, en su defecto, dar un rodeo de 36 kilómetros por carretera.

16 Al principio porque Coipasi era el único que tenía cementerio y, posteriormente, aunque cada comunidad construyó el suyo, porque había costumbre de celebrar Todos los Santos allí. Esta costumbre estuvo determinada los primeros años por el recuerdo de los recientemente fallecidos. Por ejemplo, son los tres primeros en los que hay que celebrarle durante Todos los Santos para que el alma pueda marcharse posteriormente en paz.

17 Nos dice don Anastasio Huaranca respecto de la costumbre de los de Mojotorillo con los "angelitos": "los de Mojotorillo, entonces ahí, cuando muere un chiquito, una nenita, traíamos con charango. Cantando, bailando, con charangito. El costumbre era de ellos. Cantando, bailando, con charangito, al chiquito lo traían, al cementerio. Ahora, todo eso, ha desaparecido".

18 Tal vez la escena se pareciera a la que describe Bastien en Kaata: "Hacia media mañana el cementerio estaba repleto de mesas parecidas, fabricadas por los parientes de los muertos. Aproximadamente cuarenta ritualistas apacheteños estaban circulando orando para los muertos. Cargaban grandes sacos de pan y fruta. A los que rezaban con fervor y ofrecían velas, a los muertos les regalaron bellas figuras de pan, naranjas y bananas" (Bastien 1996:218).

19 En realidad no se realizaba en el cementerio, sino en el terreno anexo al mismo.

20 Presentado en la charla titulada " ¿Se puede hacer etnografía de los muertos? Reflexiones desde los Andes", dentro del Simposio Internacional "Etnografías de la muerte en América Latina" organizado por el Grupo de Investigación Antropología de América y el Departamento de Historia de América II (Antropología de América) de la Universidad Complutense de Madrid. 
